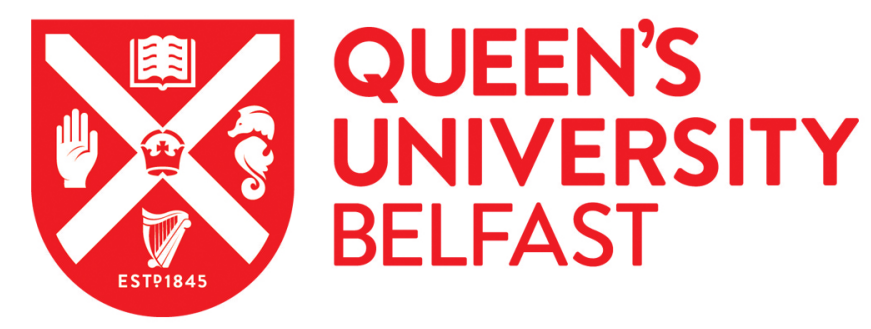

\title{
Human Seroprevalence to coxiella burnetii ( $Q$ fever) in Northern Ireland
}

McCaughey, C., McKenna, J., McKenna, C., Coyle, P., O'Neill, H., Wyatt, D. E., Smyth, B., \& Murray, L. (2008). Human Seroprevalence to coxiella burnetii (Q fever) in Northern Ireland. Public Health, 55(4), $189-194$.

\section{Published in:}

Public Health

\section{Queen's University Belfast - Research Portal:}

Link to publication record in Queen's University Belfast Research Portal

\section{General rights}

Copyright for the publications made accessible via the Queen's University Belfast Research Portal is retained by the author(s) and / or other copyright owners and it is a condition of accessing these publications that users recognise and abide by the legal requirements associated with these rights.

Take down policy

The Research Portal is Queen's institutional repository that provides access to Queen's research output. Every effort has been made to ensure that content in the Research Portal does not infringe any person's rights, or applicable UK laws. If you discover content in the Research Portal that you believe breaches copyright or violates any law, please contact openaccess@qub.ac.uk. 
ORIGINAL ARTICLE

\title{
Human Seroprevalence to Coxiella burnetii (Q fever) in Northern Ireland
}

\author{
C. McCaughey ${ }^{1}$, J. McKenna ${ }^{1}$, C. McKenna ${ }^{1}$, P. V. Coyle ${ }^{1}$, H. J. O'Neill ${ }^{1}$, D. E. Wyatt ${ }^{1}$, \\ B. Smyth ${ }^{2}$ and L. J. Murray ${ }^{3}$ \\ 1 Regional Virus Laboratory, Kelvin Building, Belfast Health and Social Care Trust, Royal Victoria Hospital, Belfast BT12 6BA, UK
2 Communicable Disease Surveillance Centre, CDSC (NI), McBrien Building, Belfast City Hospital, Lisburn Road, Belfast BT9 7AB, UK
${ }^{3}$ Department of Epidemiology and Public Health, Queen's University of Belfast, Mulhouse, Belfast BT12 6BJ, UK
}

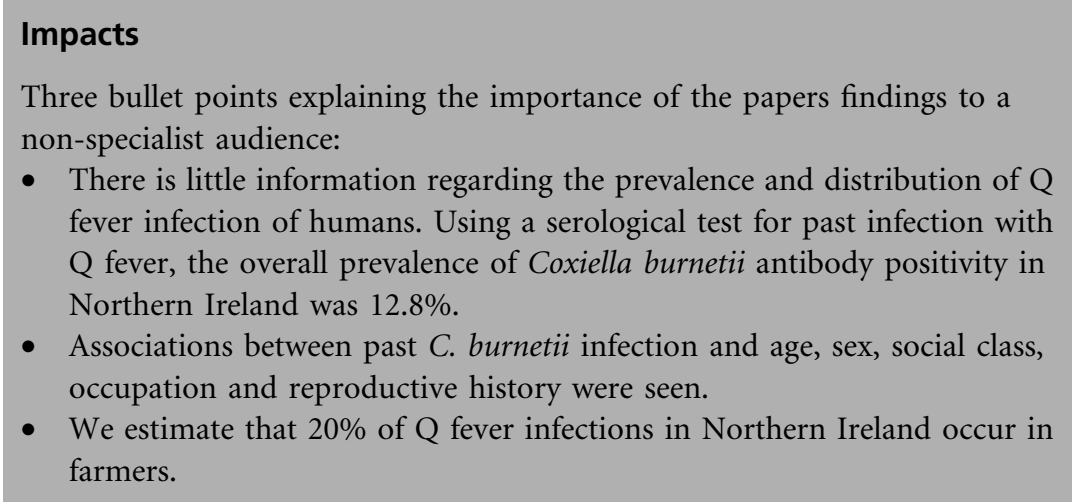

Keywords:

Coxiella burnetii; Q fever; seroprevalence; Northern Ireland; human; distribution; determinants

\section{Correspondence:}

Dr Conall McCaughey. Consultant Virologist, Regional Virus Laboratory, Belfast Health and Social Care Trust, Royal Victoria Hospital, Belfast BT12 6BA, UK.

Tel.: +44(0)289063 5239;

Fax: +44(0)28 9023 3454;

E-mail: conall.mccaughey@belfasttrust. hscni.net

Received for publication August 20, 2007

doi: 10.1111/j.1863-2378.2008.01109.x

\begin{abstract}
Summary
Despite the widespread prevalence of infection with Coxiella burnetii, there have been few large population-based studies examining the epidemiology of this infection. The aim of this study was to examine the distribution and determinants of C. burnetii past infection in Northern Ireland (NI). Coxiella burnetii phase II specific IgG antibodies were measured by enzyme-linked immunosorbent assay in stored serum from 2394 randomly selected subjects, aged 12-64, who had participated in population-based surveys of cardiovascular risk factors performed in 1986 and 1987. The overall prevalence of C. burnetii antibody positivity was $12.8 \%$. The prevalence of sero-positivity was slightly higher in males than that in females $(14.3 \%$ versus $11.2 \%, P=0.02)$. Sero-positivity was low in children $(<10 \%)$, increasing to $19.5 \%$ and $16.4 \%$ in males and females, respectively, in the 25-34 age group and subsequently remaining fairly steady with increasing age. Sero-positivity among farmers, at $48.8 \%$, was significantly higher than the general population. More sero-positive than sero-negative women had a history of a miscarriage or still-birth (19.5\% versus $9.8 \%$, $P<0.001)$. In conclusion, this study demonstrated a high prevalence of evidence of past C. burnetii infection in NI. Associations between past C. burnetii infection and age, sex, social class, occupation and reproductive history were seen. We estimate that $20 \%$ of Q fever infections in NI occur in farmers.
\end{abstract}

\section{Introduction}

Q fever is a common, globally distributed, zoonotic infection caused by the obligate intracellular gammaproteobacterial organism, Coxiella burnetii (Cutler et al., 2007). Many mammals and birds can be infected and human infection has been associated with both avian and mammalian sources (Maurin and Raoult, 1999). The livestock most often implicated in human disease are cattle, sheep and goats (Maurin and Raoult, 1999). Transmission to humans is believed to be particularly associated with contact with parturient animals (Maurin and Raoult, 1999). 
A large proportion of human cases of C. burnetii infection is asymptomatic (Terheggen and Leggat, 2007). Where symptomatic infection occurs, typical signs and associated symptoms are headache, pyrexia and respiratory tract infection including atypical pneumonia. Indeed, these were the presenting features in a recent abattoirassociated outbreak in Scotland (Cutler et al., 2007). Hepatitis may also occur. Chronic infection is well recognized, usually in the form of Q fever endocarditis or vascular graft infection (O'Donnell et al., 2007).

Compared to the rest of the British Isles, Northern Ireland (NI) historically reports particularly high rates of symptomatic Q fever in humans, with typically between 10 and 75 cases per year since 1990 in a population of 1.6 million (0.6-4.7 cases per 100000 (Communicable Disease Surveillance Centre Northern Ireland, 2007).

Agriculture is more important to the NI economy than it is in other regions of the UK and livestock farming is a key part of the NI economy. The cattle population comprises approximately 1.7 million animals on approximately 32000 farms and the sheep population comprises more than 2 million animals (Department of Agriculture and Rural Development, 2007). There is no significant goat farming component in NI. More frequent animal to human contact in NI due to the ruminant to human ratio may contribute to the higher rates of symptomatic $Q$ fever compared to the rest of the UK. However, little is known about the prevalence of asymptomatic infection and in general there is a paucity of data on prevalence of C. burnetii infection in the British Isles and a lack of understanding of the determinants of infection (Cutler et al., 2007).

\section{Materials and Methods}

In this study, stored serum from adolescents and adults throughout NI who participated in cross-sectional surveys [the Change of Heart $(\mathrm{COH})$ Baseline Study and the Countrywide Integrated Non-communicable Diseases Intervention (CINDI) study (http://www.euro.who.int/ CINDI/)] of cardiovascular risk factors in the late 1980s was tested anonymously for evidence of past infection with $\mathrm{Q}$ fever.

\section{Survey methods}

Similar methods were used in both CINDI and $\mathrm{COH}$ Baseline surveys. Between September 1987 and July 1988, subjects aged 12-24 were recruited into the CINDI survey and subjects aged 25-64 into the $\mathrm{COH}$ Baseline Survey. Subjects were randomly selected using a two stage process: selection of clusters (General Practices) stratified by Health Board area (four Boards in NI), followed by selection of patients, aged 12-64, registered with the practices. Within each Board, General Practices were randomly selected with probability proportional to the size of the practice (number of male and female patients aged under 65 years registered with the practice). In each selected practice, a random sample of 15 patients was obtained in each of the four age/sex strata (males aged 12-34, 35-64 years; females aged 12-34, 35-64 years). Interviews and a clinical examination were undertaken in Health Centres, GP's surgeries or other suitable Health Service, Education and Library Board or Blood Transfusion Service accommodation. Subjects completed a selfadministered questionnaire collecting data on education, occupation (adults), medical history, family and personal history of cardiovascular disease, medications, normal dietary intake, adherence to specific diets, exercise and other lifestyle factors. Social class was coded according to the Office of Population Censuses and Surveys 1980 Classification of Occupations. In this classification, farmers are classified as non-manual workers. A health examination was undertaken which consisted of anthropometric measurements, blood pressure measurement, using the Hawksley Random-Zero Sphygmomanometer, ECG recording and blood sampling. Twenty millilitres of blood was drawn under standardized conditions. Blood was immediately refrigerated and was centrifuged on site. Samples were returned to the central laboratory in Belfast where they were stored at $-70^{\circ} \mathrm{C}$. The samples were thawed and immediately refrozen on a maximum of three occasions prior to testing for antibodies to $\mathrm{Q}$ fever.

\section{Q fever enzyme-linked immunosorbent assay testing}

The presence of IgG antibodies to Phase II C. burnetii in the serum specimen was detected using a commercially available indirect enzyme-linked immunosorbent assay (ELISA) test kit (Vircell, Granada, Spain; Cat. No. G1001). The standard manufacturer's protocol was followed for testing, use of controls and interpretation of results. The antigen used in the Vircell IgG assay is C. burnetii phase II Nine Mile, grown in cell culture. The cut off for a positive test result was based on the manufacturer's stipulated guidelines. An antibody index [(sample $\mathrm{OD} /$ cut off serum mean OD) $\times 10$ ] determined and interpreted in line with the manufacturer's guidance as follows: $<9$ negative; $9-11$ equivocal; $>11$ positive. The assay will identify individuals with current infection as well as past infection.

\section{Statistical methods}

In all the analyses, equivocal antibody tests were treated as negative. For comparison of age and social class distri- 
bution of participants for whom serum was available with those for whom it was not available, chi-squared test was used. The prevalence of sero-positivity for IgG antibodies to $C$. burnetii was compared between relevant groups using the chi-squared test. Where relevant, the age- and sex-adjusted odds of sero-positivity were compared between groups using multiple logistic regression analysis with odds ratios and 95\% confidence intervals (95\% CI) reported. Independent samples $t$-tests were used to compare the mean level of continuous variables, such as BMI, systolic and diastolic blood pressure between sero-positives and sero-negatives, with multiple linear regression used to adjust for potential confounders where appropriate. Social class and occupational analyses were restricted to subjects aged 25 and over to avoid inclusion of students attending second and third level education for whom occupational data were not available. All analyses were performed using spss for Windows, Version 12.0.1 (SPSS Inc., Chicago, IL, USA).

\section{Results}

In all, 6080 subjects were selected for inclusion in the CINDI and $\mathrm{COH}$ Baseline surveys. Two-thousand eighthundred and fifty (51\% female) of these subjects were recruited, giving an overall participation rate of $47 \%$. However, $6.8 \%$ of subjects could not be traced, most likely because the details of their registration with the General Practice were not up to date. The response rate among traced subjects was $50.3 \%$. The age and sex distribution of participants in the surveys is shown (Table 1).

Serum was available for testing in this study from 2394 participants (84\%) and the age and social class distribution of participants for whom serum was available was the same as those for whom it was not available (age $P=0.83$ social class distribution $P=0.58$ ). There was no difference in the availability of serum from the CINDI and $\mathrm{COH}$ Baseline surveys. All subsequent analyses relate to subjects for whom serum was available. The relationship between various factors and Q fever sero-positivity is shown (Table 2).

Table 1. Age and sex distribution of subjects

\begin{tabular}{ccc}
\hline & Males no. (\%) & Females no. (\%) \\
\hline $\begin{array}{c}\text { Age group (years) } \\
12-15\end{array}$ & $293(21.1)$ & $324(22.1)$ \\
$16-24$ & $395(28.5)$ & $414(28.3)$ \\
$25-34$ & $148(10.7)$ & $142(9.7)$ \\
$35-44$ & $226(16.3)$ & $222(15.2)$ \\
$45-54$ & $193(13.9)$ & $187(12.8)$ \\
$55-64$ & $131(9.5)$ & $175(12.0)$ \\
Total & 1386 & 1464 \\
\hline
\end{tabular}

Serum from 306 participants (12.8\%) tested positively for IgG antibodies to Phase II C. burnetii, and in a further 38 subjects $(1.6 \%)$ the result was equivocal. The prevalence of $\mathrm{Q}$ fever sero-positivity was slightly higher in males than that in females $(14.3 \%$ versus $11.2 \%$, $P=0.02)$. Sero-positivity was low in the children $(<10 \%)$, increasing to $19.5 \%$ and $16.4 \%$ in males and

Table 2. Relationship between various factors and $Q$ fever seropositivity

\begin{tabular}{|c|c|c|c|}
\hline Factor & $\begin{array}{l}\text { Sero-negative } \\
\text { no. }(\%)\end{array}$ & $\begin{array}{l}\text { Sero-positive } \\
\text { no. }(\%)\end{array}$ & $P$-value \\
\hline \multicolumn{4}{|l|}{ Age group (years) } \\
\hline $12-15$ & $474(92.9)$ & $36(7.1)$ & \multirow[t]{6}{*}{$<0.001$} \\
\hline $16-24$ & $619(91.0)$ & $61(9.0)$ & \\
\hline $25-34$ & $205(82.0)$ & $45(18.0)$ & \\
\hline $35-44$ & $309(82.6)$ & $65(17.4)$ & \\
\hline $45-54$ & $272(84.5)$ & $50(15.5)$ & \\
\hline $55-64$ & $209(81.0)$ & $49(19.0)$ & \\
\hline \multicolumn{4}{|l|}{ Sex } \\
\hline Male & $1015(85.7)$ & $170(14.3)$ & \multirow[t]{2}{*}{0.023} \\
\hline Female & $1073(88.8)$ & $136(11.2)$ & \\
\hline \multicolumn{4}{|l|}{ Social class* } \\
\hline Non-manual & $400(78.0)$ & $113(22.0)$ & \multirow[t]{2}{*}{0.001} \\
\hline Manual & $498(85.4)$ & $85(14.6)$ & \\
\hline \multicolumn{4}{|l|}{ Occupation* } \\
\hline Farmer & $44(51.2)$ & $42(48.8)$ & \multirow[t]{2}{*}{$<0.001$} \\
\hline Other & $951(85.1)$ & $167(14.9)$ & \\
\hline \multicolumn{4}{|l|}{ Reproductive history ${ }^{\dagger}$} \\
\hline $\begin{array}{l}\text { Miscarriage or } \\
\text { still-birth }\end{array}$ & $153(80.5)$ & $37(19.5)$ & \multirow[t]{2}{*}{$<0.001$} \\
\hline $\begin{array}{l}\text { No miscarriage or } \\
\text { still-birth }\end{array}$ & $914(90.2)$ & $99(9.8)$ & \\
\hline \multicolumn{4}{|l|}{ Smoking status } \\
\hline Never smoked & $1232(88.3)$ & $163(11.7)$ & \multirow[t]{4}{*}{0.001} \\
\hline Ex-smoker & $262(80.9)$ & $62(19.1)$ & \\
\hline Current smoker $<20$ & $369(89.8)$ & $42(10.2)$ & \\
\hline Current smoker 20 or more & $224(85.2)$ & $39(14.8)$ & \\
\hline
\end{tabular}

Difference in mean values (sero-positives minus sero-negatives)

Unadjusted Adjusted ${ }^{*}$
No. $(95 \% \mathrm{Cl}) \quad(95 \% \mathrm{Cl})$

\begin{tabular}{llll}
\hline Height $(\mathrm{cm})$ & 2383 & $1.15(-0.09$ to 2.40$)$ & $-0.01(-1.05$ to 1.04$)$ \\
Weight $(\mathrm{kg})$ & 2382 & $3.71(1.96$ to 5.47$)$ & $0.54(-0.94$ to 2.01$)$ \\
BMI $\left(\mathrm{kg} / \mathrm{m}^{2}\right)$ & 2381 & $1.06(0.53$ to 1.60$)$ & $0.23(-0.25$ to 0.70$)$ \\
$\begin{array}{l}\text { Systolic blood } \\
\text { pressure }\end{array}$ & 2391 & $5.03(2.69$ to 7.37$)$ & $0.48(-1.46$ to 2.43$)$ \\
$\begin{array}{l}\text { (mmHg) } \\
\text { Diastolic blood } \\
\text { pressure }\end{array}$ & 2391 & $3.91(2.26$ to 5.56$)$ & $0.96(-0.46$ to 2.39$)$ \\
\begin{tabular}{l} 
(mmHg) \\
\hline
\end{tabular} & & & \\
\hline
\end{tabular}

*Includes only subjects aged 25 and over.

tWomen only.

*Adjusted for age and sex. 


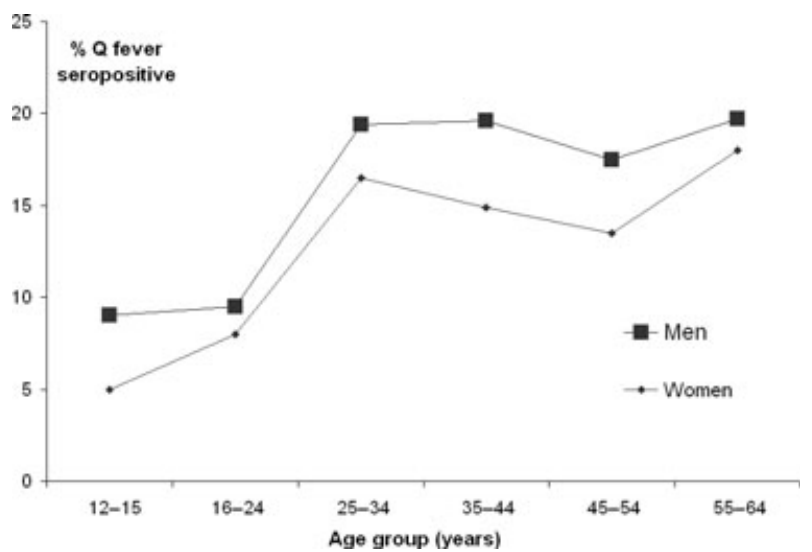

Fig. 1. Prevalence of sero-positivity for IgG antibodies to Phase ॥ Coxiella burnetii by age and sex.

females, respectively, in the 25-34 age group and remaining fairly steady with increasing age beyond this. The shape of the curve of sero-positivity by age between the sexes was very similar (Fig. 1).

In subjects aged 25 and over, sero-positivity was associated with social class: $22.0 \%$ of subjects from non-manual social classes was sero-positive compared to $14.6 \%$ from manual classes $(P=0.02)$. The age- and sex-adjusted odds ratio $(95 \% \mathrm{CI})$, for infection in non-manual compared to manual social classes was 1.79 (1.30-2.47). The dataset of subjects aged 25 and over included subjects whose occupation (or occupation of the head of the household) was recorded as farmer (43 males and 43 females). Sero-positivity among farmers was $48.8 \%$ $(55.8 \%$ and $41.9 \%$ in male and female farmers respectively) compared to $15.4 \%$ in the rest of the population, giving an age- and sex-adjusted odds ratio (95\% CI) for infection in farmers compared to non-farmers of 5.33 (3.36-8.46). When farmers were removed from the social class analysis, the sero-positivity rate was no different between the manual and non-manual social classes (16.6\% and $14.6 \%$ respectively, $P=0.37$ ). Among subjects aged 25 and over for whom occupational data were available, $21.2 \%$ of the positive cases was farmers.

Sero-positivity appeared to be related to being an ex-smoker (Table 2), but this relationship did not survive the adjustment for age and sex: odds ratio (95\% CI) ex-smokers compared to non-smokers, 1.18 (0.83-1.68).

$\mathrm{Q}$ fever sero-positivity was not related to height, weight, BMI or systolic or diastolic blood pressure after adjustment for age and sex (Table 2).

More sero-positive women had a history of a miscarriage or still-birth (Table 2 ). Women farmers were more likely to have had a history of miscarriage or still-birth than other women $(26.8 \%$ versus $15.9 \%, P=0.03)$. However, the relationship between sero-positivity and miscarriage or still-birth was not attenuated by adjustment for age, farming occupation and number of children: odds ratio $(95 \% \mathrm{CI})$ of miscarriage or still-birth in sero-positive compared to sero-negative women, 1.81 (1.12-2.94).

\section{Discussion}

Very little data are available on human seroprevalence to C. burnetii in the UK population. We have previously demonstrated a prevalence of $7.8 \%$ in an urban (Belfast based) population (McCaughey et al., 2005). This study, using stored serum samples from subjects recruited throughout NI, a mixed rural/urban population, showed an overall prevalence of $12.8 \%$. A previous study in England showed a seroprevalence of $10.9 \%$ in a cohort of 395 police and emergency service personnel from five English local authority districts (Thomas et al., 1995). Reported seroprevalence in other European countries varies greatly ranging from $4 \%$ to $45 \%$ and international comparisons are particularly difficult because of varying test methods and cut offs especially in older studies. In Cyprus, the seroprevalence, using IgG immunofluorescence to C. burnetii phase II antigen, was estimated at $52.7 \%$ (Psaroulaki et al., 2006). A seroprevalence study of blood donors in Switzerland also using a phase II IgG immunofluorescence test revealed a seroprevalence of $10.9 \%$ in urban areas and 17\% in rural areas (Dupuis et al., 1986). In Germany, the seroprevalence was found to be $22 \%$ found in blood donors and military personnel in the 1980s using a phase II IgG ELISA assay (Schmeer et al., 1987). A seroprevalence of 4\% was found in 942 blood donors in Marseille, France, in 1988 using a phase II IgG immunofluorescence test (Tissot et al., 1992). Our seroprevalence determination for NI fell within the typical range from the literature.

In general, previous studies have not had detailed demographic information on subjects. We were able to examine the associations between sero-positivity and age, sex, social class occupation and reproductive history.

The response rates in our study were fairly low and therefore have the potential to introduce selection bias. However, any selection bias on the basis of sero-positivity seems unlikely. The sera were collected 20 years ago and therefore are essentially historical. The number of recognized cases varies from year to year and aspects of farming practice may have changed in this 20 -year period but it is difficult to predict a specific impact of these changes on seroprevalence.

There was a predominance of young people in this sample. This has proven useful for examining the likely age of acquisition of $\mathrm{Q}$ fever in the population. There was 
a significant increase in prevalence through the 12-15, 16-24 and 25-34 years age bands followed by a plateau. This clearly suggests that infection is mainly acquired in adolescence and early adulthood with very little further acquisition of infection after 35 years of age. Although unlikely, an alternative interpretation is that this could be a birth cohort effect. We cannot exclude this possibility without follow-up which is not possible in the current study. Previous studies have indicated that there is a reduced likelihood of clinically symptomatic infection in children and adolescents (Maltezou and Raoult, 2002; Maltezou et al., 2004). The basis for this phenomenon remains unclear.

Smoking history was not associated with seroprevalence. Previous literature has suggested an association between smoking status and Q fever (Ayres et al., 1998; Wildman and Ayres, 2000; Hatchette et al., 2001). In the large outbreak of Q fever pneumonia in Birmingham, UK in 1989, $60(55 \%)$ of 110 patients for whom smoking data were available were current smokers, 28 (25\%) were ex-smokers, and only 22 (20\%) had never smoked although there was not a clear comparison with the general population or an age- and sex-matched group of unaffected subjects (Wildman and Ayres, 2000). A subsequent case-control study in the same cohort demonstrated smoking to be a risk factor for $\mathrm{Q}$ fever with $32.4 \%$ of cases being current smokers compared to $16.9 \%$ of controls $(P=0.022)$ (Ayres et al., 1998). Smoking was also shown to be an independent risk factor for acquisition of $\mathrm{Q}$ fever infection in goat workers in rural Newfoundland (Hatchette et al., 2001). However, our previous work (McCaughey et al., 2005) clearly indicated no relationship between past smoking and Q fever seroprevalence. The current study provides further support for this finding as although sero-positivity initially appeared to be related to being an ex-smoker (Table 2), this relationship did not survive adjustment for age and sex.

Smoking may reflect the extent of hand to mouth contact which may be important in transmission of the infection, especially in an occupational exposure setting. Alternatively, smokers may be more likely to get symptomatic rather than asymptomatic disease due to some form of smoking induced pulmonary compromise. Our finding of no association between smoking status and seroprevalence in both this and our previous study would tend to favour the second explanation, assuming that the reported association with smoking and symptomatic Q fever is valid.

There is a clear social class gradient in evidence of past infection (higher social classes are more likely to be seropositive) but this is explained by farmers (who are coded as non-manual workers in this dataset). At least one-fifth of all sero-positive subjects were farmers but the propor- tion of infections occurring in farmers may actually be higher as occupational coding was on the basis of main occupation and the social class of part-time farmers were coded on the basis of their other occupation. Therefore, more than one-fifth of the Q fever infections in NI may be acquired through farming but it is likely that there are other important methods of exposure, some of which may be occupation related.

No association with cardiovascular risk factors was found. This is in keeping with our previous observations that there is no association between serological evidence of past C. burnetii infection and incident ischaemic heart disease smoking, lipid levels, or inflammatory markers (McCaughey et al., 2005).

An interesting and unexpected observation was that sero-positive women were almost twice as likely to have had a miscarriage or still-birth as sero-negative women and this was not confounded by farming occupation. This may indicate that Q fever sero-positivity is not acting as a proxy for some other farming related infection that may cause abortions in humans such as Chlamydophila abortus, Brucella or unknown abortifacient agents associated with farm exposure (Agerholm et al., 2006). Caution is required in interpreting this finding and confirmation is required from other studies. Obstetric complications are well-recognized sequelae of symptomatic acute $\mathrm{Q}$ fever in pregnant women (Carcopino et al., 2007). Our findings raise the question of whether there is also evidence for an association with asymptomatic or chronic infection in humans, which could be plausible given the predilection of this organism for placenta, and its behaviour in other mammals. Obviously in this sample, timing of $\mathrm{Q}$ fever infection in relation to pregnancy, and whether $\mathrm{Q}$ fever was symptomatic or asymptomatic, are unknown. No symptomatic cases of Q fever would have been anticipated among these 1464 female participants, based on a Q fever rate of 0.6-4.7 per 100000 . We suggest that further research would be warranted into the possibility that $C$. burnetii infection may be a more significant cause of human miscarriage or still-birth than previously recognized.

The overall seroprevalence of $12.8 \%$ in the NI population is further evidence of the ubiquity of infection with this zoonotic agent in human populations in Europe. There is insufficient data available regarding the public health action that can be taken to develop preventative strategies for high-risk occupations such as farmers. In the absence of surveillance, we do not know if standard hygiene measures are effective in prevention of $\mathrm{Q}$ fever infection nor what activity on farms are most important in exposure. Introduction of Q fever vaccination for abattoir workers and other recognized at-risk occupational groups in certain affected Australian states in 2001 led to a fall in rates from peaks of up to 18 cases per 100000 , 
to 2-4 per 100000 (Yohannes et al., 2006). We are currently undertaking a study of farmers to determine the likely risk exposure activities. We hope that this will help to inform debate on introduction of vaccination of agricultural workers in the British Isles.

\section{Acknowledgements}

The authors wish to thank all the men and women who volunteered to be participants in the Change of Heart $(\mathrm{COH})$ Baseline and CINDI studies.

The authors wish to thank the three anonymous reviewers whose comments greatly improved the finished paper.

\section{Funding}

This serological study was funded by a grant from the Research \& Development Office, a Directorate of the NI Health and Social Services Central Services Agency (RRG project 9.8).

The Change of Heart Baseline and NI Countrywide Integrated Non-communicable Diseases Intervention (CINDI) Programme were funded by Department of Health and Social Services (NI) and the NI Chest Heart and Stroke Association.

\section{References}

Agerholm, J. S., B. Aalbaek, A. M. Fog-Larsen, M. Boye, E. Holm, T. K. Jensen, T. Lindhardt, L. E. Larsen, and D. Buxton, 2006: Veterinary and medical aspects of abortion in Danish sheep. APMIS 114, 146-152.

Ayres, J. G., N. Flint, E. G. Smith, W. S. Tunnicliffe, T. J. Fletcher, K. Hammond, D. Ward, and B. P. Marmion, 1998: Post-infection fatigue syndrome following Q fever. QJM 91, 105-123.

Carcopino, X., D. Raoult, F. Bretelle, L. Boubli, and A. Stein, 2007: Managing Q fever during pregnancy: the benefits of long-term cotrimoxazole therapy. Clin. Infect. Dis. 45, 548555.

Communicable Disease Surveillance Centre Northern Ireland, 2007: Laboratory Reports of Coxiella burnetii 1995-2006 Northern Ireland. Available at: http://www.cdscni.org.uk/ surveillance/Respiratory/Coxiella_burnetii.htm (last accessed on 30 January, 2008).

Cutler, S. J., M. Bouzid, and R. R. Cutler, 2007: Q fever. J. Infect. 54, 313-318.

Department of Agriculture and Rural Development, 2007: The Agricultural Census in Northern Ireland: Results for June 2006. Available at: http://www.dardni.gov.uk/ j06-final-results.pdf (last accessed on 30 January, 2008).

Dupuis, G., O. Peter, M. C. Mottiez, and M. Vouilloz, 1986: [Seroprevalence of human Q fever in Switzerland]. Schweiz. Med. Wochenschr. 116, 494-498.
Hatchette, T. F., R. C. Hudson, W. F. Schlech, N. A. Campbell, J. E. Hatchette, S. Ratnam, D. Raoult, C. Donovan, and T. J. Marrie, 2001: Goat-associated Q fever: a new disease in Newfoundland. Emerg. Infect. Dis. 7, 413-419.

Maltezou, H. C., and D. Raoult, 2002: Q fever in children. Lancet Infect. Dis. 2, 686-691.

Maltezou, H. C., I. Constantopoulou, C. Kallergi, V. Vlahou, D. Georgakopoulos, D. A. Kafetzis, and D. Raoult, 2004: Q fever in children in Greece. Am. J. Trop. Med. Hyg. 70, 540544.

Maurin, M., and D. Raoult, 1999: Q fever. Clin. Microbiol. Rev. 12, 518-553.

McCaughey, C., L. J. Murray, J. P. McKenna, P. V. Coyle, H. J. O’Neill, D. E. Wyatt, J. V. Woodside, J. W. Yarnell, P. Ducimetiere, A. Bingham, P. Amouyel, M. Montaye, D. Arveiler, B. Haas, J. Ferrieres, and J. B. Ruidavets, 2005: Lack of association between serological evidence of past Coxiella burnetii infection and incident ischaemic heart disease: nested case-control study. BMC. Infect. Dis. 5, 61.

O’Donnell, M. E., N. Manshani, C. McCaughey, C. Soong, and B. Lee, 2007: Coxiella burnetii infection of an aortic graft with multiple vertebral body erosion. J. Vasc. Surg. 45, 399403.

Psaroulaki, A., C. Hadjichristodoulou, F. Loukaides, E. Soteriades, A. Konstantinidis, P. Papastergiou, M. C. Ioannidou, and Y. Tselentis, 2006: Epidemiological study of Q fever in humans, ruminant animals, and ticks in Cyprus using a geographical information system. Eur. J. Clin. Microbiol. Infect. Dis. 25, 576-586.

Schmeer, N., H. Krauss, D. Werth, and H. G. Schiefer, 1987: Serodiagnosis of Q fever by enzyme-linked immunosorbent assay (ELISA). Zentralbl. Bakteriol. Mikrobiol. Hyg. [A] 267, $57-63$.

Terheggen, U., and P. A. Leggat, 2007: Clinical manifestations of Q fever in adults and children. Travel. Med. Infect. Dis. 5, 159-164.

Thomas, D. R., L. Treweek, R. L. Salmon, S. M. Kench, T. J. Coleman, D. Meadows, P. Morgan-Capner, and E. O. Caul, 1995: The risk of acquiring Q fever on farms: a seroepidemiological study. Occup. Environ. Med. 52, 644-647.

Tissot, D. H., D. Raoult, P. Brouqui, F. Janbon, D. Peyramond, P. J. Weiller, C. Chicheportiche, M. Nezri, and R. Poirier, 1992: Epidemiologic features and clinical presentation of acute Q fever in hospitalized patients: 323 French cases. Am. J. Med. 93, 427-434.

Wildman, M., and J. G. Ayres, 2000: Long term vascular complications of Coxiella burnetii infection. Cardiovascular risk factors cannot be ignored. BMJ 320, 58-59.

Yohannes, K., P. W. Roche, A. Roberts, C. Liu, S. M. Firestone, M. Bartlett, I. East, B. P. Hull, M. D. Kirk, G. L. Lawrence, A. McDonald, P. B. McIntyre, R. I. Menzies, H. E. Quinn, and C. Vadjic, 2006: Australia's notifiable diseases status, 2004, annual report of the National Notifiable Diseases Surveillance System. Commun. Dis. Intell. 30, $1-79$. 